\title{
Improving Performance in Core Business Classes
}

\author{
Stanko Racic \\ Robert Morris University \\ Gayle J. Marco \\ Robert Morris University \\ Frank Flanegin \\ Robert Morris University
}

\begin{abstract}
Results from t-test and regression analysis suggests that female and transfer students at RMU do not require additional tutoring but warrant continuous monitoring and readiness to provide extra help if necessary. Age seems to be a less important indicator of academic success for undergraduate than graduate business students. Sequencing of prerequisites and their timing relative to when the core classes are taken does not appear to be important. However, statistically significant regression coefficient for MATH2040 grades more than twice that for MATH1010 grades in regressions for ACCT2060, ECON1020 and FINA3000 grades indicates that MATH1010 should be replaced with MATH2060 as prerequisite.
\end{abstract}

Keywords: performance, business, classes

\section{INTRODUCTION}

On April 1 $1^{\text {st }}$, 2009, The School of Business (BSBA) at Robert Morris University (RMU) successfully completed the Association to Advance Collegiate School of Business (AACSB) accreditation process. As the years have passed, both the rules and the requirements for re-accreditation have changed, but one concept that has never waivered is the need to "Close the Loop". This paper is an extension and expansion of a paper titled "Assurance of Learning, Closing the Loop: Utilizing a Pre and Post Test for Principles of Finance" by [Flanegin, et al., 2010]. From an accreditation perspective "Closing the Loop" requires the identification of a problem and the ability to identify/implement solutions. The aforementioned paper found that students who took MATH2040 - Applied Calculus class did significantly better in the Principles of Finance Class than those who took MATH1010 - College Mathematics or remedial MATH0900 Elementary Algebra. The end result of the above research was to make MATH2040 a prerequisite for the Principles of Finance class and hence we "closed the loop".

While the changes implemented from the first study improved student results in the Principles of Finance class, other core business classes (Accounting, Economics, Management and Marketing) were not reviewed and still suffered from lower than desired student performance. In today's competitive academic marketplace, it is not only important to enhance the quality of our student's education, but also to maximize 
our ability to retain students. Hence, the Retention Committee's charge was to review how successful students were in completing the BSBA degree and identify changes that could improve students' success.

Literature review revealed several factors hypothesized to impact students' performance. While [Christensen, et al., 2012] found little correlation between MBA students' performance and "traditional" indicators, such as college QPA and GMAT scores, results for "alternative" determinants of performance were mixed. Gender had no statistical importance and age was statistically significant predictor of success. [Woosley \& Callahan, 2011] attributed the lower performance of undergraduate "transfer students" relative to "native students" to the disruption in continuity of courses progression relative to specific prerequisites for different institutions. Course sequencing was also recognized as paramount to mapping student achievement and performance by [Cuevas, et al., 2010].

Given the proposed determinants of students' performance in the literature, the comprehensive data on students provided to us by the RMU and the task of Retention Committee, of which several authors were members, we decided to analyze the relationship between students' performance and its hypothesized factors in order to make recommendations that might improve students' success in core business classes. Depending on results ere considering additional tutoring for transfer and female students, introducing MATH2040 as prerequisite for all core classes, and if necessary enforcing stricter sequencing and eliminating time lags between the time prerequisites and core classes are taken. In addition, we also wanted to check if high school grade point average might be a better indicator of future students' performance than traditional SAT scores, in order to make a better selection at the time of students' admission.

\section{DATA AND T-TEST OF DIFFERENCE IN MEAN FOR VARIOUS SUBSAMPLES}

Our sample of 2,286 students who were registered in core business classes (ACCT2060 - Managerial Accounting, ECON1020 - Principles of Macroeconomics, FINA3000 - Principles of Finance, MGMT3100 - Managerial Theory and Practice, and MARK3100 - Principles of Marketing), from Fall 2010 through Fall 2012, excluding Summer classes, is summarized in Table 1.

TABLE 1

NUMBER OF STUDENTS REGISTERED IN CORE BUSINESS CLASSES

\begin{tabular}{|l|l|l|l|l|l|}
\hline Term & ACCT2060 & ECON1020 & FINA3000 & MGMT3100 & MARK3100 \\
\hline Fall 2012 & 247 & 258 & 155 & 237 & 286 \\
\hline Spring 2012 & 189 & 240 & 171 & 217 & 250 \\
\hline Fall 2011 & 226 & 268 & 160 & 213 & 251 \\
\hline Spring 2011 & 143 & 241 & 151 & 182 & 215 \\
\hline Fall 2010 & 204 & 279 & 184 & 209 & 243 \\
\hline
\end{tabular}

Data, from official RMU sources, included: high school GPA; verbal and math SAT scores (SATV and SATM, respectively); freshman term; if they started at RMU or transferred; major; term in which core business and math classes were taken with earned grades; as well as age and college QPA at the time they finished each of core courses.

Algebraic means for different subsamples were compared by testing the null hypothesis that the difference of the mean $\left(\bar{X}_{i}\right)$ for two populations of different size $\left(n_{i}\right)$, with unknown and unequal variances $\left(S_{i}^{2}\right)$ are equal to zero, using the Welch t-statistic:

$$
t=\frac{\bar{X}_{1}-\bar{X}_{2}}{\sqrt{S_{1}^{2} / n_{1}+S_{2}^{2} / n_{2}}}
$$

with the appropriate degrees of freedom calculated using the following formula: 


$$
d f \approx \frac{\left(S_{1}^{2} / n_{1}+S_{2}^{2} / n_{2}\right)^{2}}{\frac{\left(S_{1}^{2} / n_{1}\right)^{2}}{\left(n_{1}-1\right)}+\frac{\left(S_{2}^{2} / n_{2}\right)^{2}}{\left(n_{2}-1\right)}}
$$

Demographic characteristics for the entire sample and subsamples of students who started at RMU or natives versus students who transferred from another university, are presented in Table 2. For the overall sample, female students (762 of 2,286 or $33.33 \%$ of the entire sample) were significantly younger with higher high school and college average grade, but lower math SAT score than male students at $1 \%$ statistical level.

Transfer students (672 of 2,286 or $29.40 \%$ of the entire sample) were significantly older, with lower average grades in both high school and college, and worse scores in every SAT category than RMU students at $1 \%$ statistical level.

TABLE 2

DEMOGRAPHICS FOR THE ENTIRE SAMPLE AND NATIVE V TRANSFER STUDENTS

\begin{tabular}{|c|c|c|c|c|c|c|}
\hline \multirow{2}{*}{ Category } & \multirow{2}{*}{ Number } & \multicolumn{5}{|c|}{ Average } \\
\hline & & Age & HS GPA & Coll QPA & SATV & SATM \\
\hline Sample & 2286 & 22.42 & 3.33 & 3.16 & 502.23 & 537.95 \\
\hline Female & 762 & 21.95 & 3.50 & 3.26 & 502.59 & 525.77 \\
\hline $\begin{array}{l}\text { Male } \\
(t \text {-statistics })\end{array}$ & 1524 & $\begin{array}{r}22.65 \\
4.41^{* * * *}\end{array}$ & $\begin{array}{r}3.24 \\
10.23^{* * *} \\
\end{array}$ & $\begin{array}{r}3.10 \\
6.07^{* * * *}\end{array}$ & $\begin{array}{r}502.04 \\
0.14 \\
\end{array}$ & $\begin{array}{l}544.06 \\
4.22^{* * *}\end{array}$ \\
\hline Natives & 1614 & 21.25 & 3.36 & 3.18 & 504.88 & 543.22 \\
\hline Native Female & 548 & 21.18 & 3.52 & 3.32 & 504.74 & 531.43 \\
\hline Native Male & 1066 & 21.29 & 3.28 & 3.11 & 504.95 & 549.12 \\
\hline $\begin{array}{l}\text { Transfers } \\
(t \text {-statistics })\end{array}$ & 672 & $\begin{array}{r}25.21 \\
19.09^{* * *}\end{array}$ & $\begin{array}{r}3.07 \\
6.13^{* * * *} \\
\end{array}$ & $\begin{array}{r}3.10 \\
2.82^{* * * *}\end{array}$ & $\begin{array}{l}478.30 \\
4.07^{* * *}\end{array}$ & $\begin{array}{l}490.61 \\
7.25^{* * *}\end{array}$ \\
\hline $\begin{array}{l}\text { Transfer Female } \\
\text { (t-statistics) }\end{array}$ & 214 & $\begin{array}{r}23.92 \\
9.55^{\text {**** }}\end{array}$ & $\begin{array}{r}3.36 \\
2.20^{* *}\end{array}$ & $\begin{array}{r}3.11 \\
4.13^{* * * *}\end{array}$ & $\begin{array}{l}483.68 \\
2.01^{* *}\end{array}$ & $\begin{array}{l}475.79 \\
4.71^{\text {**** }}\end{array}$ \\
\hline $\begin{array}{l}\text { Transfer Male } \\
\text { (t-statistics) }\end{array}$ & 458 & $\begin{array}{r}25.82 \\
16.87^{* * *}\end{array}$ & $\begin{array}{r}2.93 \\
6.18^{* * * *}\end{array}$ & $\begin{array}{l}3.09 \\
0.39\end{array}$ & $\begin{array}{l}475.51 \\
3.54^{* * * *}\end{array}$ & $\begin{array}{l}498.22 \\
5.60^{* * * *}\end{array}$ \\
\hline
\end{tabular}

${ }^{*},{ }^{* *}$ and ${ }^{*}$ denote statistically significant difference at $1 \%, 5 \%$ and $10 \%$ level.

In order to preserve space, t-test for business majors were nor reported. Students enrolled in quantitative majors (accounting, economics and finance) had higher average grades in high school and college than remaining business students (enrolled in hospitality, management, marketing, sports management, and undeclared).

Arithmetic average grades in core business classes for the entire sample and subsamples of native versus transfer students are shown in Table 3. Overall, female students had a significantly higher grade at 1\% statistical level in MGMT3100 and MARK3100, and at 5\% statistical level in ECON1020. There was no statistically significant difference in average grade based on gender in either ACCT2060 or FINA3000. 
TABLE 3

CORE CLASSES GRADES FOR THE ENTIRE SAMPLE AND NATIVE V TRANSFER STUDENTS

\begin{tabular}{|c|c|c|c|c|c|c|c|c|c|c|}
\hline \multirow{2}{*}{ Category } & \multicolumn{2}{|c|}{ ACCT2060 } & \multicolumn{2}{|c|}{ ECON1020 } & \multicolumn{2}{|c|}{ FINA3000 } & \multicolumn{2}{|c|}{ MGMT3100 } & \multicolumn{2}{|c|}{ MARK3100 } \\
\hline & Obs. & Grade & Obs. & Grade & Obs. & Grade & Obs. & Grade & Obs. & Grade \\
\hline Sample & 1222 & 2.77 & 1501 & 2.76 & 908 & 2.66 & 1152 & 3.05 & 1231 & 2.81 \\
\hline Female & 405 & 2.82 & 537 & 2.84 & 324 & 2.70 & 385 & 3.18 & 421 & 2.97 \\
\hline $\begin{array}{l}\text { Male } \\
\text { (t-statistics) }\end{array}$ & 817 & $\begin{array}{l}2.74 \\
1.23\end{array}$ & 964 & $\begin{array}{r}2.72 \\
2.24^{* *}\end{array}$ & 584 & $\begin{array}{l}2.64 \\
1.00\end{array}$ & 767 & $\begin{array}{r}2.98 \\
4.05^{* * * *} \\
\end{array}$ & 810 & $\begin{array}{r}2.74 \\
4.45^{* * *}\end{array}$ \\
\hline Natives & 916 & 2.77 & 1297 & 2.77 & 654 & 2.69 & 894 & 3.05 & 916 & 2.84 \\
\hline Native Female & 316 & 2.83 & 463 & 2.88 & 238 & 2.73 & 309 & 3.22 & 322 & 3.00 \\
\hline Native Male & 600 & 2.74 & 834 & 2.71 & 416 & 2.67 & 585 & 2.95 & 594 & 2.76 \\
\hline $\begin{array}{l}\text { Transfers } \\
(t \text {-statistics })\end{array}$ & 306 & $\begin{array}{l}2.75 \\
0.29\end{array}$ & 204 & $\begin{array}{l}2.68 \\
1.12\end{array}$ & 254 & $\begin{array}{l}2.58 \\
1.51^{*}\end{array}$ & 258 & $\begin{array}{l}3.07 \\
0.41\end{array}$ & 315 & $\begin{array}{r}2.73 \\
1.82^{* *}\end{array}$ \\
\hline $\begin{array}{l}\text { Transfer Female } \\
\text { (t-statistics) }\end{array}$ & 89 & $\begin{array}{l}2.78 \\
0.42\end{array}$ & 74 & $\begin{array}{r}2.57 \\
2.06^{* * *}\end{array}$ & 86 & $\begin{array}{l}2.61 \\
1.01\end{array}$ & 76 & $\begin{array}{r}3.03 \\
1.69^{* *}\end{array}$ & 99 & $\begin{array}{l}2.85 \\
1.47^{*}\end{array}$ \\
\hline $\begin{array}{l}\text { Transfer Male } \\
\text { (t-statistics) }\end{array}$ & 217 & $\begin{array}{l}2.74 \\
0.03\end{array}$ & 130 & $\begin{array}{l}2.74 \\
0.30\end{array}$ & 168 & $\begin{array}{l}2.57 \\
1.11\end{array}$ & 182 & $\begin{array}{r}3.09 \\
1.97^{* *}\end{array}$ & 216 & $\begin{array}{l}2.68 \\
1.04\end{array}$ \\
\hline
\end{tabular}

${ }^{*},{ }^{* *}$ and ${ }^{*}$ denote statistically significant difference at $1 \%, 5 \%$ and $10 \%$ level.

Lower FINA3000 and MARK3100 average grades for all transfer students and lower ECON1020 and MGMT3100 average grades for female transfer students indicate that non-native RMU students, especially if they transferred from community colleges, may need additional assistance and this may warrant continuous monitoring of their progress.

Business students in quantitative majors (accounting, economics and finance) had statistically higher average grades in all core business classes than remaining business students (hospitality, management, marketing, sports management and undeclared).

\section{REGRESSION ANALYSIS}

To better understand the forces behind reported differences in mean between different subsamples, regression analysis was performed using OLS for the determinants of overall QPA and the grades in core business classes. To avoid scaling issues of grades ranging from 0 to 4 versus SAT scores ranging from 0 to 800 , all variables were converted from their levels to percentage of the maximum value. For every dependent variable, college QPA or core class grade, we started with the initial or full model including all variables hypothesized to affect it, as described in Table 4. In subsequent regressions, the least significant variable was excluded and the process repeated until we discovered the model with the largest number of significant explanatory variables. In order to preserve the space only the best models were reported. 


\section{TABLE 4}

\section{EXPLANATORY VARIABLES AND THEIR EXPECTED SIGN}

\begin{tabular}{|l|l|}
\hline Variable & Definition and Expected Sign \\
\hline AGE & In years when particular class was taken. Expect positive impact of maturing. \\
\hline MALE & $\begin{array}{l}\text { Dummy variable (1 for male students). Expect negative impact for QPA and non- } \\
\text { quantitative classes (historically females perform better, but males show more aptitude } \\
\text { toward quantitative subjects). }\end{array}$ \\
\hline TR & $\begin{array}{l}\text { Dummy variable (1 for transfer students). No prior, since transfer may come from } \\
\text { community colleges (might be less well prepared than RMU students) or from higher } \\
\text { ranking institutions. }\end{array}$ \\
\hline SINCE & Number of terms since student started at RMU. Expect positive impact of maturing. \\
\hline BUS & $\begin{array}{l}\text { Dummy variable (1 for business school students). Expect positive impact of students } \\
\text { interested in business, with synergies from other business classes. }\end{array}$ \\
\hline MAJOR & $\begin{array}{l}\text { 1= Accounting, 2 = Economics, 3 = Finance, 4 = Hospitality, 5 = Management, 6 = } \\
\text { Marketing, 7 = Sports Management, 8 = Undeclared. Expect negative impact since } \\
\text { alphabetical ordering puts quantitative majors into the first three categories. Single 1/0 } \\
\text { dummy for each major was not used due to relatively small sample size. }\end{array}$ \\
\hline QPA & $\begin{array}{l}\text { Percentage of student's college QPA relative to 4. Expect positive impact of better student } \\
\text { on performance in particular core business class. }\end{array}$ \\
\hline SATV & Percentage of student's SAT Verbal score relative to 800. Expect positive impact. \\
\hline SATM & Percentage of student's SAT Math score relative to 800. Expect positive impact. \\
\hline HSGPA & Percentage of student's High School GPA relative to 4. Expect positive impact. \\
\hline MATH & $\begin{array}{l}\text { Percentage of student's grade in MATH2400, MATH1010 or MATH0900 relative to 4. } \\
\text { Expect positive impact. }\end{array}$ \\
\hline BTW & $\begin{array}{l}\text { Number of semesters between math and core business classes were taken. Expect negative } \\
\text { impact of deteriorating math skills from passage of time. }\end{array}$ \\
\hline
\end{tabular}

Results from regression analysis of determinants of QPA are presented in Table 5. With exception of AGE and BUS all explanatory variables have hypothesized effect on QPA and are significant at the 1\% statistical level. Positive impact of the transfer dummy suggests that we are getting more students from higher ranking institutions than from community colleges. Note that HSGPA seems to be a better predictor of QPA then either SATV or SATM, which is in accordance with many colleges putting less emphasis or completely disregarding scores from SAT or ACT, and using HSGPA and other indicators to select freshmen students. Dropping BUS or AGE did not make the other variable statistically significant and hence the initial specification is also the best model.

To analyze the determinants of students' success in core classes we regressed the grades from each core class against the explanatory variables from Table 4, repeating the analysis for each of the three math classes separately. Models using MATH0900 grades had fewer statistically significant determinants than those that used MATH1010 or MATH2040 grades as explanatory variables, and hence were not reported. 
TABLE 5

DETERMINANTS OF QPA

\begin{tabular}{|c|c|c|}
\hline QPA & The Best Model & \\
\hline Adjusted $\mathrm{R}^{2}$ & 36.29 & \\
\hline Observations & 1603 & \\
\hline & Coeff & t Stat \\
\hline Intercept & 12.62 & $2.64^{* * *}$ \\
\hline AGE & 0.25 & 1.56 \\
\hline MALE & -2.63 & $-4.14^{* * *}$ \\
\hline TR & 2.76 & $2.65^{* * *}$ \\
\hline BUS & 0.86 & 0.98 \\
\hline MAJOR & -0.42 & $-2.68^{* * * *}$ \\
\hline SATV & 0.21 & $5.43^{* * *}$ \\
\hline SATM & 0.14 & $3.79^{* * * *}$ \\
\hline HSGPA & 0.49 & $18.43^{* * *}$ \\
\hline
\end{tabular}

*** denotes statistical significance at $1 \%$ level.

Results from regression analysis of core classes' grades, with grades from MATH1010 and MATH2040 representing level of math skills, are provided in Tables 6 and 7, respectively. Comparison between these two tables shows that specifications including MATH2040 grades had the same or greater number of statistically significant explanatory variables and since the signs of statistically significant determinants of core class grades was the same for both MATH2040 and MATH1010 models, our discussion will focus on models with MATH2040 grades. Note that regression coefficients for MATH2040 grades were more than twice the coefficients for MATH1010 grades in regressions for ACCT2060 and ECON1020, and that only MATH2040 grades were important in explaining FINA3000 grades.

TABLE 6

GRADES IN CORE CLASSES USING MATH1010 GRADES AS DETERMINANT

\begin{tabular}{|l|r|r|r|r|r|r|r|r|r|r|}
\hline & \multicolumn{2}{|c|}{ ACCT2060 } & \multicolumn{2}{c|}{ ECON1020 } & \multicolumn{2}{c|}{ FINA3000 } & \multicolumn{2}{c|}{ MGMT3100 } & \multicolumn{2}{c|}{ MARK3100 } \\
\hline Adj R & 41.10 & & 41.36 & & 54.02 & & 38.35 & & 39.52 & \\
\hline Obs & 566 & & 547 & & 323 & & 424 & & 458 & \\
\hline & Coeff & $t$ Stat & Coeff & $t$ Stat & Coeff & $t$ Stat & Coeff & $t$ Stat & Coeff & $t$ Stat \\
\hline Intercept & -24.62 & $-3.23^{* * *}$ & -67.18 & $-4.40^{* * *}$ & -44.55 & $-4.37^{* * *}$ & 4.06 & 0.30 & -28.41 & $-4.07^{* * *}$ \\
\hline AGE & -0.36 & -1.47 & 0.64 & 1.23 & 0.20 & 0.76 & -0.18 & -0.42 & 0.54 & $2.23^{* *}$ \\
\hline MALE & 4.58 & $2.80^{* * *}$ & 6.42 & $3.60^{* * *}$ & 1.55 & 0.85 & -1.75 & -1.01 & & \\
\hline TR & 4.28 & $1.78^{* *}$ & & & -1.86 & -0.70 & 1.34 & 0.35 & & \\
\hline SINCE & & & 1.22 & $2.25^{* *}$ & 0.50 & 1.01 & 0.39 & 0.64 & 0.12 & 0.54 \\
\hline BUS & 13.85 & $4.41^{* * *}$ & 4.56 & 1.41 & 15.31 & $2.93^{* * *}$ & 0.69 & 0.20 & 6.18 & $2.76^{* * *}$ \\
\hline MAJOR & -1.10 & $-2.91^{* * *}$ & -0.11 & -0.26 & -2.42 & $-5.35^{* * *}$ & 0.28 & 0.65 & & \\
\hline QPA & 1.02 & $14.04^{* * *}$ & 1.07 & $13.19^{* * *}$ & 1.19 & $13.83^{* * *}$ & 1.13 & $12.98^{* * *}$ & 1.05 & $14.14^{* * *}$ \\
\hline SATV & & & & & & & 0.05 & 0.43 & & \\
\hline SATM & & & 0.15 & 1.21 & & & -0.07 & -0.58 & & \\
\hline HSGPA & & & 0.20 & $2.45^{* *}$ & & & -0.14 & -1.57 & & \\
\hline MATH & 0.06 & $1.66^{*}$ & 0.04 & 0.97 & 0.04 & 0.84 & -0.02 & -0.48 & -0.03 & -0.77 \\
\hline BTW & 0.59 & $3.64^{* * *}$ & -1.35 & $-2.63^{* * *}$ & -0.65 & -1.23 & -0.15 & -0.30 & & \\
\hline
\end{tabular}

$*{ }^{* * *}$ and ${ }^{*}$ indicate statistical significance at $1 \%, 5 \%$ and $10 \%$ level. 
TABLE 7

GRADES IN CORE CLASSES USING MATH2040 GRADES AS DETERMINANT

\begin{tabular}{|l|r|r|r|r|r|r|r|r|r|r|}
\hline & \multicolumn{2}{|c|}{ ACCT2060 } & \multicolumn{2}{c|}{ ECON1020 } & \multicolumn{2}{|c|}{ FINA3000 } & \multicolumn{2}{|c|}{ MGMT3100 } & \multicolumn{2}{|c|}{ MARK3100 } \\
\hline Adj R & 44.05 & & 46.02 & & 53.8 & & 42.87 & & 47.98 & \\
\hline Obs & 795 & & 921 & & 536 & & 888 & & 683 & \\
\hline & Coeff & $t$ Stat & Coeff & $t$ Stat & Coeff & $t$ Stat & Coeff & $t$ Stat & Coeff & $t$ Stat \\
\hline Intercept & -30.6 & $-3.08^{* * *}$ & -56.54 & $-5.23^{* * *}$ & -52.96 & $-6.57^{* * *}$ & -7.87 & -1.30 & -54.37 & $-5.66^{* * *}$ \\
\hline AGE & -0.41 & -1.21 & 0.66 & $1.70^{*}$ & & & -0.12 & -0.53 & 1.10 & $3.36^{* * *}$ \\
\hline MALE & 3.19 & $2.44^{* *}$ & 5.05 & $3.92^{* * *}$ & 2.53 & $1.76^{*}$ & -0.83 & -0.76 & & \\
\hline TR & 1.76 & 0.70 & & & & & 3.06 & $1.98^{* *}$ & & \\
\hline SINCE & & & 0.69 & $2.31^{* *}$ & & & 0.65 & $2.90^{* * *}$ & & \\
\hline BUS & 8.99 & $3.49^{* * *}$ & & & 13.12 & $3.19^{* * *}$ & 7.79 & $3.84^{* * *}$ & 4.52 & $1.84^{*}$ \\
\hline MAJOR & -1.04 & $-3.49^{* * *}$ & -0.36 & -1.41 & -1.61 & $-4.80^{* * *}$ & -0.54 & $-2.07^{* *}$ & 0.29 & 0.95 \\
\hline QPA & 0.81 & $12.36^{* * *}$ & 0.97 & $15.23^{* * *}$ & 1.05 & $14.32^{* * *}$ & 1.05 & $20.01^{* * *}$ & 1.16 & $18.19^{* * *}$ \\
\hline SATV & 0.23 & $2.60^{* * *}$ & 0.07 & 0.98 & 0.13 & 1.32 & & & & \\
\hline SATM & 0.21 & $2.42^{* *}$ & & & 0.16 & $1.67^{*}$ & & & & \\
\hline HSGPA & & & 0.23 & $3.88^{* * *}$ & & & & & 0.07 & 1.25 \\
\hline MATH & 0.13 & $3.77^{* * *}$ & 0.10 & $3.06^{* * *}$ & 0.13 & $3.39^{* * *}$ & -0.05 & -1.59 & -0.04 & -1.26 \\
\hline BTW & 0.48 & $1.71^{*}$ & & & -0.45 & -1.54 & -0.19 & $-0.86^{* * *}$ & 0.35 & 1.58 \\
\hline
\end{tabular}

${ }^{* * * * * * *}{ }^{*}$ and $^{*}$ indicate statistical significance at $1 \%, 5 \%$ and $10 \%$ level.

The only explanatory variable that had significant impact on all grades was QPA, consistent with the expectations that overall good students will have good grades in individual classes.

Male dummy significantly impacted all "quantitative" classes, ACCT2060, ECON1020 and FINA3000, but had no effect on MGMT3100 or MARK3100, which is contrary to t-test findings that females had statistically higher average grade in ECON1020, MGMT3100 and MARK3100. This contradiction could be due to substantial smaller number of observations in regression analysis, where presence of all explanatory variables required for observation to be used, relative to t-test, where only grades were compared. The number of observations for regression analysis of FINA3000 and MARK3100 was almost $50 \%$ smaller than for t-test.

Transfer dummy as well as the variables measuring the number of terms since students enrolled at RMU and between taking MATH2040 and core class, were important only for grades in MGMT3100, indicating that in most cases transfer students quickly fit in with native RMU students and that the sequence and timing of MATH2040 are less important for a majority of core classes.

Although both SATs and high school GPA were significant in explaining overall QPA, SATs had significant impact only on ACCT2060 and FINA3000 grades, while HS GPA significantly affected only ECON1020 grades. One possible explanation for these findings is sequencing of classes. Students usually take ECON1020 during the first two years and the rest of core classes only after they reach 70 credits. The link between material learned in high school, represented by HS GPA, and core classes other than ECON1020 weakens with passage of time. ACCT2060 is prerequisite for FINA3000, and both rely more heavily on math than other core classes. Students in quantitative majors, who usually do better on the SAT, take ACCT2060 and FINA3000 as early as possible, since they are prerequisites for electives. Students in non-elective majors, who usually perform the worst on the SAT, often leave these two classes for their senior year, and are often satisfied just with passing them.

[Christensen, et al., 2012] reported that age was the significant predictor of MBA students' performance. In our sample age marginally impacted the ECON1020 grade and was highly important for MARK3100, without affecting grades in other core classes, suggesting that age is less important for undergraduate than graduate academic achievement. 
Business majors performed significantly better than other RMU students. One possible explanation for lack of significant impact on ECON1020 is that non-business majors who elected to take ECON1020 had interest and affinity toward the material and were able to draw on their high school knowledge in more general economics class than in other more major specific core classes where business majors did better.

Business students in "quantitative" majors (accounting, economics and finance) earned higher grades in ACCT2060, FINA3000 and MGMT3100 than other business students, which is not surprising given the quantitative nature of these classes.

\section{CONCLUSIONS}

The Retention Committee of RMU's School of Business was charged with analyzing the retention and performance of business students and suggest ways to improve them. In addition to "traditional" indicators of students' success, such as high school GPA, SAT scores and college QPA, a literature review identified several "alternative" ones including gender and age. Sequencing of prerequisites was also recognized as important, especially for students who transferred from other institutions.

Demographic and academic data were collected for 2,286 students registered in core business classes (Managerial Accounting, Principles of Macroeconomics, Principles of Finance, Managerial Theory and Practice and Principles of Marketing) from Fall 2010 through Fall 2012, excluding Summer classes.

We used Welch t-test to analyze differences in average indicators of students' success for various subsample. OLS regressions were utilized to find the importance of factors affecting overall QPA and grades in cores classes.

Based on results from t-test and regression analysis it was concluded that the performance of female and transfer students does not require additional tutoring but warrants continuous monitoring and readiness to provide them if and when necessary.

Age seems to be a less important indicator of academic success for undergraduate than graduate business students.

Sequencing of prerequisites and their timing relative to when the core classes are taken does not seem to be important. However, statistically significant regression coefficient for MATH2040 grades more than twice that for MATH1010 grades in regressions for ACCT2060, ECON1020 and FINA3000 grades indicates that MATH1010 should be replaces with MATH2060 as prerequisite for core business classes.

\section{REFERENCES}

Christensen, D.G., Nance, W.R., \& White, D.W. (2012). Academic Performance in MBA Programs: Do Prerequisites Really Matter? Journal of Education for Business, 87(1), 42-47.

Cuevas, N.M., Matveev, A.G., \& Miller, K.O. (2010, Winter). Mapping General Education Outcomes in the Major: Intentionality and Transparency. $A A C \& U$, pp. 10-15.

Flanegin, F., Letterman, D., Racic, S., \& Schimmel K. (2010, September). Assurance of Learning, "Closing the Loop": Utilizing a Pre and Post Test for Principles of Finance. Journal of Case Studies in Accreditation and Assessment, 1.

Woosley, S.A., \& Callahan, T. (2011). The Effects of Prerequisites and Curricular Continuity: Domestic Versus Imported. College Student Journal, 45(3), 524-535. 